\title{
RESEARCH
}

Open Access

\section{Decline in cognitively complex everyday activities accelerates along the Alzheimer's disease continuum}

\author{
Mark A. Dubbelman 1* (D, Roos J. Jutten', Sarah E. Tomaszewski Farias², Rebecca E. Amariglio 3,4, \\ Rachel F. Buckley ${ }^{3,4,5}$, Pieter Jelle Visser ${ }^{1,6}$, Dorene M. Rentz ${ }^{3,4}$, Keith A. Johnson ${ }^{3,7}$, Michael J. Properzi ${ }^{3}$, \\ Aaron Schultz ${ }^{3}$, Nancy Donovan ${ }^{4,8}$, Jennifer R. Gatchell ${ }^{9}$, Charlotte E. Teunissen ${ }^{10}$, Bart N. M. Van Berckel ${ }^{11}$, \\ Wiesje M. Van der Flier ${ }^{1}$, Reisa A. Sperling ${ }^{3,4}$, Kathryn V. Papp ${ }^{3,4}$, Philip Scheltens' ${ }^{1}$, Gad A. Marshall ${ }^{3,4}$, \\ Sietske A. M. Sikkes ${ }^{1,12}$ and for the Alzheimer Disease Neuroimaging Initiative, National Alzheimer's Coordinating \\ Center, the Harvard Aging Brain Study, the Alzheimer Dementia Cohort
}

\begin{abstract}
Background: Impairment in daily functioning is a clinical hallmark of dementia. Difficulties with "instrumental activities of daily living" (IADL) seem to increase gradually over the course of Alzheimer's disease (AD), before dementia onset. However, it is currently not well established how difficulties develop along the preclinical and prodromal stages of AD. We aimed to investigate the trajectories of decline in IADL performance, as reported by a study partner, along the early stages of AD.
\end{abstract}

Methods: In a longitudinal multicenter study, combining data from community-based and memory clinic cohorts, we included 1555 individuals (mean age $72.5 \pm 7.8$ years; $50 \%$ female) based on availability of amyloid biomarkers, longitudinal IADL data, and clinical information at baseline. Median follow-up duration was 2.1 years. All amyloidpositive participants $(n=982)$ were classified into the National Institute on Aging-Alzheimer's Association (NIA-AA) clinical stages ranging from preclinical $A D(1)$ to overt dementia (4+). Cognitively normal amyloid-negative individuals $(n=573)$ served as a comparison group. The total scores of three study-partner reported IADL questionnaires were standardized.

Results: The rate of decline in cognitively normal (stage 1$)$ individuals with and without abnormal amyloid did not differ $(p=.453)$. However, from stage 2 onwards, decline was significantly faster in individuals on the AD continuum $(B[95 \% C l]=-0.32[-0.55,-0.09], p=.007)$. The rate of decline increased with each successive stage: one standard deviation (SD) unit per year in stage $3(-1.06[-1.27,-0.85], p<.001)$ and nearly two SD units per year in stage $4+$ $(1.93[-2.19,-1.67], p<.001)$. Overall, results were similar between community-based and memory clinic study cohorts.

\footnotetext{
* Correspondence: m.dubbelman@amsterdamumc.nl

'Department of Neurology, Amsterdam Neuroscience, Alzheimer Center

Amsterdam, Vrije Universiteit Amsterdam, Amsterdam UMC, location VUmc,

P.O. Box 7057, 1007 MB Amsterdam, The Netherlands

Full list of author information is available at the end of the article
}

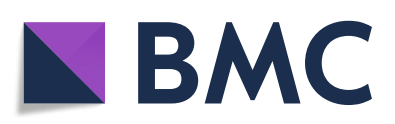

(- The Author(s). 2020 Open Access This article is licensed under a Creative Commons Attribution 4.0 International License, which permits use, sharing, adaptation, distribution and reproduction in any medium or format, as long as you give appropriate credit to the original author(s) and the source, provide a link to the Creative Commons licence, and indicate if changes were made. The images or other third party material in this article are included in the article's Creative Commons licence, unless indicated otherwise in a credit line to the material. If material is not included in the article's Creative Commons licence and your intended use is not permitted by statutory regulation or exceeds the permitted use, you will need to obtain permission directly from the copyright holder. To view a copy of this licence, visit http://creativecommons.org/licenses/by/4.0/. The Creative Commons Public Domain Dedication waiver (http://creativecommons.org/publicdomain/zero/1.0/) applies to the data made available in this article, unless otherwise stated in a credit line to the data. 


\begin{abstract}
(Continued from previous page)
Conclusions: Our results suggest that the rate of functional decline accelerates along the AD continuum, as shown by steeper rates of decline in each successive NIA-AA clinical stage. These results imply that incremental changes in function are a meaningful measure for early disease monitoring. Combined with the low-cost assessment, this advocates the use of these functional questionnaires for capturing the effects of early AD-related cognitive decline on daily life.
\end{abstract}

Keywords: Alzheimer's disease, functional impairment, instrumental activities of daily living, clinical stages

\section{Background}

Alzheimer's disease (AD) pathology, consisting of amyloidbeta plaques, tau neurofibrillary tangles, and neurodegeneration, develops for numerous years before leading to hallmark clinical signs of cognitive and functional impairment [1]. The earliest clinical signs of $\mathrm{AD}$ appear to be the subjective experience of memory decline [2, 3], followed by subtle changes in higher-order cognitive functioning. The effects of cognitive decline in daily life can be captured in the performance of cognitively complex "instrumental activities of daily living" (IADL), such as cooking, managing personal and financial paperwork, and keeping appointments.

Impairment in daily functioning is traditionally described as occurring relatively late in the $\mathrm{AD}$ disease trajectory, i.e., as a core characteristic of dementia. However, increasing evidence demonstrates that everyday functioning declines gradually over the years preceding the clinical diagnosis of dementia. This has been shown in a number of crosssectional studies [4-12], as well as a few longitudinal studies [13-17]. Measuring IADL functioning is important, as it is a clinically relevant outcome measure [18], affecting not only the patient, but also their support system by increasing financial [19] and caregiver burden [20]. Moreover, IADL measures have strong ecological validity and they are related directly to daily life. As such, they are valuable in both clinical practice and research.

Individuals with abnormal amyloid are in the Alzheimer's continuum, and they can be classified into six stages based on clinical symptom severity, according to the U.S. National Institute on Aging-Alzheimer's Association (NIA-AA) research framework [1]. People in stage 1 (the preclinical phase) do not report a decline in cognition and perform normally on cognitive tests. Stages 2 and 3 (the prodromal phase) are characterized by a self-reported decline in cognition but normal performance on cognitive tests, and the emergence of the first objectified cognitive impairments, respectively. Stages 4 through 6 represent overt dementia with increasing severity of both cognitive and functional impairment. The question remains at what point along the disease trajectory changes in IADL functioning actually start to occur, and how this decline in function develops along the $\mathrm{AD}$ continuum.

In this study, we focus especially on the earliest stages $(1-3)$, as we hypothesize that a decline in function may already be present here. We aimed to determine how $\mathrm{IADL}$ functioning progresses along the $\mathrm{AD}$ continuum, as well as to identify the stage in which decline in functioning is accelerated compared to amyloid-negative, cognitively normal controls. Finally, we aimed to investigate specific activities in more detail, to determine whether there were any differences in the advent of problems and rate of decline in relatively easy and relatively complex IADLs.

\section{Methods \\ Study cohorts and selection criteria}

We selected subjects from six cohorts: Harvard Aging Brain Study (HABS, $n=259$ ), Alzheimer's Disease Neuroimaging Initiative (ADNI, $n=829$ ), National Alzheimer's Coordinating Center (NACC, $n=201$ ), Amsterdam Dementia Cohort (ADC, $n=178$ ), European Medical Information Framework (EMIF)-AD PreclinAD Study $(n=73)$, and EMIF-AD 90+ Study $(n=15)$.

Specific procedures have been described for each cohort in detail elsewhere [21-26]. Briefly, HABS is a prospective community-based cohort that consists of individuals aged 65 years and older, who are considered cognitively normal at study inclusion [21]. ADNI is a multicenter longitudinal cohort study. For the present study, we obtained baseline and follow-up data acquired for ADNI-GO and ADNI-2 [22]. The NACC database contains mostly memory-clinic referred subjects with additional community recruitment [23]. The $\mathrm{ADC}$ is a memory-clinic cohort comprised of patients of the Alzheimer Center Amsterdam [24]. In the EMIF-AD PreclinAD Study, cognitively normal subjects aged 60 years and older were included [25]. The EMIF-AD 90+ Study focused on people aged 90 years and older who were either cognitively normal or who had some cognitive impairment [26].

For the present study, subjects were selected based on (1) availability of amyloid biomarkers at baseline, (2) sufficient information to determine NIA-AA clinical staging at baseline, and (3) availability of longitudinal IADL data, defined as having at least one follow-up assessment. All data used in this study were collected between June 2002 and July 2019.

All studies were approved by ethical review boards, and all subjects provided written informed consent for 
the use of their data for research purposes, in accordance with the Declaration of Helsinki.

\begin{abstract}
Amyloid
Amyloid status was assessed at baseline using either amyloid positron emission tomography (PET) imaging or cerebrospinal fluid (CSF) using local procedures, such as described in more detail elsewhere [25-30]. PET scans, using ${ }^{11} \mathrm{C}$-Pittsburgh compound-B (PiB) in HABS, ${ }^{18} \mathrm{~F}$-florbetapir in ADNI, and one of ${ }^{11} \mathrm{C}$-PiB, ${ }^{18} \mathrm{~F}$-flutemetamol, ${ }^{18} \mathrm{~F}$-florbetapir, or ${ }^{18} \mathrm{~F}$-florbetaben in the ADC and EMIF cohorts, were judged either using standard uptake volume ratios (ADNI, NACC), distribution volume ratios (HABS), or visual rating by independent nuclear medicine physicians (ADC, both EMIF studies). For CSF, local cutoffs for amyloid positivity were used (NACC, ADC). Where both PET and CSF were available for the same individual $(n=66)$, PET results were favored. Both amyloid-positive and amyloid-negative individuals were included. Additional details about amyloid assessment can be found in the Supplementary Material.
\end{abstract}

\section{Clinical stages}

Amyloid-positive individuals were categorized into four clinical stages according to the NIA-AA framework [1], based on baseline measures of subjective cognitive complaints, cognitive performance, and global functional impairment. This procedure and the measures used are described in detail by Jutten et al. [31]. Briefly, we considered a visit to a memory clinic, or a positive response to a subjective cognitive decline questionnaire as an indication of subjective complaints. Cognitive performance was determined using the scores on a general cognitive screener and a story or list learning task. Finally, functional impairment was determined using a global dementia rating scale. The IADL instruments used as outcomes were not used to determine the stages. Baseline stages are defined as follows: (1) no complaints and no cognitive deficits, objectified using standard neuropsychological testing; (2) subjective complaints but no objectified cognitive deficits; (3) mild objectified cognitive deficits; and (4+) clinically manifest dementia. We did not distinguish between the NIA-AA stages 4, 5 and 6 , as the focus of the current investigation was on the preclinical [1] and prodromal stages [2, 3].

Cognitively normal amyloid-negative individuals without cognitive complaints or objectified deficits were included as available from the same cohorts, as a comparison group.

\section{IADL measures}

Three study partner-reported IADL instruments were used: the Functional Activities Questionnaire (FAQ),
Everyday Cognition (ECog), and Amsterdam IADL Questionnaire (A-IADL-Q).

The FAQ is a 10-item scale [32]. Each item is rated from 0 (no difficulty or independent) to 3 (dependent), as compared to performance 1 month earlier. We summed all items to compute a total score, ranging from 0 to 30 , with higher scores indicating more functional dependence. The ECog is a questionnaire comprised of 39 items reflecting cognitively complex everyday activities across 6 subscales, including memory, language, and executive functioning [33,34]. All items are rated from 1 (no change in function compared to 10 years ago) to 4 (consistently much worse function than 10 years ago). Total scores are a weighted average ranging from 1 to 4, with higher scores indicating more problems in everyday functioning. The A-IADL-Q is aimed at assessing cognitively complex, relevant everyday activities [35]. It has been extensively validated [36-40]. Item scores range from 0 (no difficulty performing the activity) to 4 (unable to perform the activity), comparing current performance to the past. Total scores are calculated using item response theory and have a mean score of 50 with a standard deviation (SD) of 10 in a memoryclinic population. Higher scores indicate better functioning.

\section{Harmonizing IADL measurements}

FAQ and ECog raw total scores were inverted so that higher scores represent better functioning. Individual instrument total scores were converted to $Z$-scores using the baseline mean and SD of the entire amyloid-negative subsample. Next, a single $Z$-score was created by pooling the individual instrument $Z$-scores into one. In instances where individuals had both a completed FAQ and ECog, we first averaged the $Z$-scores of the FAQ and ECog, before combining them into the final $Z$-score. The final IADL $Z$-score is thus a standardized measure of IADL performance, with higher scores representing better functioning. A one-unit difference in the IADL $Z$-score represents a change of one SD in functioning among cognitively normal, amyloid-negative individuals.

Furthermore, we harmonized items that referenced the same activities and were shared between the instruments. To illustrate how specific IADLs develop over time, we selected two of these activities on opposite ends on the spectrum of IADL complexity: one relatively easy item ("preparing hot beverages"), and one relatively complex item ("managing the paperwork"). The selection was made a priori on the basis of A-IADL-Q item parameters, as presented by Jutten et al. [37]. The easier item may not be impaired until a relatively high level of overall IADL impairment has been reached, whereas the more complex item may already be impaired at a lower 
overall level of IADL impairment. The harmonized items are shown in Table 1.

\section{Statistical analyses}

Linear or logistic regressions were used to investigate baseline group differences between the amyloid-negative group and each of the four NIA-AA stages. Significance was set at $p<0.01$. To analyze change over time in IADL functioning, linear mixed models (LMMs) with random intercepts and slopes were run using the "lme4" package version 1.1-27 [41] for R. LMMs are a powerful method for analyzing change over time when handling unbalanced data, including inconsistent time intervals between follow-up measurements and missing data [41]. We fitted models in which the IADL $Z$-score was the dependent variable, and time in years was the main independent variable. Interactions between stage and time were included to determine slopes for each stage, treating the amyloid-negative group as "stage 0 " for convenience. Adjustments for clustering within study cohorts, as well as for age at baseline, sex, and education, were also included. Unstandardized estimates and 95\% confidence intervals are reported for fixed effects. Finally, we ran sensitivity analyses to investigate potential differences between community-based and memory clinic studies, as well as the influence of each cohort. We ran ordinal logistic mixed-effects models on the two activities, similar to the main analyses. All analyses were run in $\mathrm{R}$ version 4.0.2 [42] and Stata version 14 [43].

\section{Results}

\section{Sample characteristics}

A total of 1555 individuals were included (age $72.5 \pm 7.8$ years old; $49.8 \%$ female), of whom 982 were amyloid positive. Mean age did not differ between amyloidpositive and amyloid-negative individuals $(p=.619)$. Amyloid-positive individuals had received fewer years of education and had lower MMSE scores at baseline (both $p<.001)$ than amyloid-negative individuals. Table 2 displays the baseline characteristics of the amyloid-negative and amyloid-positive groups. Characteristics per cohort can be found in the Supplementary Material.

All amyloid-positive individuals were classified into one of the NIA-AA clinical stages at baseline: 120 individuals $(12 \%)$ were in stage $1,160(16 \%)$ in stage 2,464 (47\%) in stage 3, and the remaining $238(24 \%)$ in stage $4+$. Individuals in stages 1 and 2 were older than those in stages 3 and 4 , had more years of education, and were more likely to be female (Table 2).

\section{Overall IADL functioning trajectories}

At baseline, 1077 participants completed the ECog, 1025 completed the FAQ, and 266 completed the A-IADL-Q. The correlation between the ECog and FAQ was $r=.83$ (95\% confidence interval $=[.81, .85], n=819)$.

At baseline, amyloid-negative (mean $(\mathrm{M}) \pm$ standard deviation $(\mathrm{SD})=0.05 \pm 0.9$ ) and amyloid-positive individuals in stage $1(0.18 \pm 0.6)$ had similar levels of IADL functioning, on average $(p=.631)$. Those in stages $2(-0.60 \pm 1.6), 3(-$ $3.76 \pm 3.3)$, and $4+(-8.75 \pm 4.3)$ each had lower baseline functioning. IADL functioning remained fairly stable over time in cognitively normal amyloid-negative individuals $(B=$ $-0.08,95 \% \mathrm{CI}=[-0.28,0.14], p=.453)$. In contrast, a substantial decline in IADL functioning was found in the amyloid-positive group as a whole $(-0.95,95 \% \mathrm{CI}=[-1.20$, -0.69 ], $p<.001$; see Table 3).

We found that, as a group, individuals in stage 1 showed a small, non-significant decline in IADL functioning over

Table 1 Harmonization of items and response options from the FAQ, ECog, and A-IADL-Q

\begin{tabular}{|c|c|c|c|}
\hline Harmonization & FAQ & ECog & A-IADL-Q \\
\hline Cohort(s) & ADNI, NACC & ADNI, HABS & ADC, EMIF pre-AD and $90+$ \\
\hline \multicolumn{4}{|l|}{ Item content } \\
\hline Hot beverages & $\begin{array}{l}\text { Heating water, making a cup of coffee, turning off the } \\
\text { stove }\end{array}$ & - & Using the coffee maker \\
\hline Paperwork & Assembling tax records, business affairs, or other papers & $\begin{array}{l}\text { Keeping financial records } \\
\text { organized }\end{array}$ & $\begin{array}{l}\text { Managing their household } \\
\text { paperwork }\end{array}$ \\
\hline \multicolumn{4}{|l|}{ Response options } \\
\hline Normal (4) & Normal (0) & Better or no change (1) & No more difficult $(0)$ \\
\hline $\begin{array}{l}\text { Slightly worse } \\
\text { (3) }\end{array}$ & Has difficulty, but does by self (1) & $\begin{array}{l}\text { Questionable/occasionally worse } \\
(2)\end{array}$ & Slightly more difficult (1) \\
\hline Worse (2) & - & Consistently a little worse (3) & More difficult (2) \\
\hline Much worse (1) & Requires assistance (2) & - & Much more difficult (3) \\
\hline Unable (0) & Dependent (3) & Consistently much worse (4) & $\begin{array}{l}\text { No longer able to perform this task } \\
\text { (4) }\end{array}$ \\
\hline
\end{tabular}

Abbreviations: ADC Amsterdam Dementia Cohort, ADNI Alzheimer's Disease Neuroimaging Initiative, A-IADL-Q Amsterdam Instrumental Activities of Daily Living Questionnaire, ECog Everyday Cognition, EMIF European Medical Information Framework, FAQ Functional Activities Questionnaire, HABS Harvard Aging Brain Study, NACC National Alzheimer's Coordinating Center 
Table 2 Baseline demographics

\begin{tabular}{|c|c|c|c|c|c|c|c|c|}
\hline & $\begin{array}{l}\text { Total group } \\
(n=1555)\end{array}$ & $\begin{array}{l}\text { Amyloid } \\
\text { negative } \\
(n=573)\end{array}$ & $\begin{array}{l}\text { Amyloid } \\
\text { positive } \\
(n=982)\end{array}$ & $\begin{array}{l}\text { Stage } 1 \\
(n=120)\end{array}$ & $\begin{array}{l}\text { Stage } 2 \\
(n=160)\end{array}$ & $\begin{array}{l}\text { Stage } 3 \\
(n=464)\end{array}$ & $\begin{array}{l}\text { Stage 4+ } \\
(n=238)\end{array}$ & $\begin{array}{l}\text { Post hoc group } \\
\text { differences }\end{array}$ \\
\hline $\begin{array}{l}\text { Years of follow-up, } \\
\text { mean (range) }\end{array}$ & $\begin{array}{l}2.79 \\
(0.25-7.09)\end{array}$ & $\begin{array}{l}3.31 \\
(0.46-7.07)\end{array}$ & $\begin{array}{l}2.49 \\
(0.25-7.09)\end{array}$ & $\begin{array}{l}2.94 \\
(0.56-6.38)\end{array}$ & $\begin{array}{l}2.96 \\
(0.46-7.06)\end{array}$ & $\begin{array}{l}2.69 \\
(0.25-7.09)\end{array}$ & $\begin{array}{l}1.36 \\
(0.26-4.45)\end{array}$ & $\begin{array}{l}\text { Amyloid negative, } \\
\text { stages } 1,2>3>4\end{array}$ \\
\hline Age & $72.45 \pm 7.8$ & $72.82 \pm 7.1$ & $72.24 \pm 8.2$ & $74.72 \pm 6.5$ & $74.19 \pm 7.7$ & $71.79 \pm 8.0$ & $70.55 \pm 9.1$ & $\begin{array}{l}\text { Stage } 1,2>\text { amyloid } \\
\text { negative }>\text { stages } 3,4\end{array}$ \\
\hline Female, n (\%) & $763(50)$ & $311(55)$ & $452(47)$ & $66(56)$ & $84(54)$ & $196(43)$ & $106(45)$ & $\begin{array}{l}\text { Amyloid negative, } \\
\text { stages } 4,2,1>3\end{array}$ \\
\hline Education years & $15.37 \pm 3.3$ & $15.94 \pm 3.1$ & $15.05 \pm 3.4$ & $15.94 \pm 3.2$ & $15.68 \pm 3.2$ & $15.13 \pm 3.3$ & $14.01 \pm 3.7$ & $\begin{array}{l}\text { Amyloid negative, } \\
\text { stage } 1,2>3>4\end{array}$ \\
\hline MMSE & $27.08 \pm 3.8$ & $29.11 \pm 1.1$ & $25.62 \pm 4.3$ & $29.06 \pm 1.0$ & $28.45 \pm 1.7$ & $26.43 \pm 2.7$ & $20.08 \pm 4.2$ & $\begin{array}{l}\text { Amyloid negative, } \\
\text { stage } 1>2>3>4\end{array}$ \\
\hline \multicolumn{9}{|l|}{ Cohorts, $n$ (\%) } \\
\hline HABS & $259(17)$ & $194(34)$ & $65(6)$ & $38(31)$ & $27(17)$ & - & - & \\
\hline ADNI & 829 (53) & $323(55)$ & $506(52)$ & $49(42)$ & $72(45)$ & $288(62)$ & $98(41)$ & \\
\hline NACC & $201(13)$ & - & $201(21)$ & $29(25)$ & $23(14)$ & $84(18)$ & $65(27)$ & \\
\hline$A D C$ & $178(11)$ & - & 178 (18) & - & $15(9)$ & $87(19)$ & $76(32)$ & \\
\hline EMIF-AD & $73(5)$ & $53(9)$ & $20(2)$ & $2(2)$ & $18(11)$ & - & - & \\
\hline EMIF-90+ & $15(1)$ & $3(1)$ & $12(1)$ & $2(2)$ & $5(3)$ & $5(1)$ & - & \\
\hline
\end{tabular}

All are displayed as mean \pm standard deviation, except as stated otherwise. Missing: Gender ( $n=22)$, education ( $n=13)$, MMSE ( $n=192)$, age ( $n=14)$. Group differences between amyloid negative and each of the four NIA-AA stages are based on linear (for all but gender) or logistic (for gender) regression Abbreviations: $A D C$ Amsterdam Dementia Cohort, ADNI Alzheimer's Disease Neuroimaging Initiative, EMIF European Medical Information Framework, HABS Harvard Aging Brain Study, MMSE Mini-Mental State Examination, NACC National Alzheimer's Coordinating Center

Table 3 Linear mixed model results of change over time in IADL functioning at baseline for amyloid negatives and amyloid positives, divided into the NIA-AA stages

\begin{tabular}{llll}
\hline Groups & $\boldsymbol{B}$ & $\mathbf{9 5 \% C l}$ & $\boldsymbol{P}$ value \\
\hline Intercepts & & & \\
Amyloid negative & -1.48 & {$[-3.46,0.31]$} & $\mathbf{-}^{\mathrm{a}}$ \\
Amyloid positive & -7.31 & {$[-9.88,-4.74]$} & $<.001^{\mathrm{a}}$ \\
Stage 1 & -0.80 & {$[-2.64,1.04]$} & $.631^{\mathrm{a}}$ \\
Stage 2 & -1.65 & {$[-3.48,0.17]$} & $.005^{\mathrm{a}}$ \\
Stage 3 & -4.67 & {$[-6.43,-2.92]$} & $<.001^{\mathrm{a}}$ \\
Stage 4+ & -9.64 & {$[-11.41,-7.88]$} & $<.001^{\mathrm{a}}$ \\
Slopes & & & \\
Amyloid negative & -0.08 & {$[-0.28,0.14]$} & .453 \\
Amyloid positive & -0.94 & {$[-1.20,-0.69]$} & $<.001$ \\
Stage 1 & -0.12 & {$[-0.37,0.13]$} & .342 \\
Stage 2 & -0.32 & {$[-0.55,-0.09]$} & .007 \\
Stage 3 & -1.06 & {$[-1.27,-0.85]$} & $<.001$ \\
Stage 4+ & -1.93 & {$[-2.19,-1.67]$} & $<.001$ \\
\hline
\end{tabular}

Shown here are unstandardized betas, adjusted for clustering within study, as well as for baseline age, gender, and years of education. The betas represent $Z$-score intercepts and yearly change (stage and time $\times$ stage interactions). ${ }^{a}$ Compared to amyloid-negative group

Abbreviations: IADL instrumental activities of daily living, 95\%Cl 95\% confidence interval time $(B=-0.12,95 \% \mathrm{CI}=[-0.37,0.13], p=.342)$. The rate of decline was only marginally larger than in the amyloidnegative group, and this difference was also not significant. Individuals in stage 2 declined significantly $(B=-$ $0.32,95 \% \mathrm{CI}=[-0.55,-0.09], p=.007)$, as did individuals in stages $3(B=-1.06,95 \% \mathrm{CI}=[-1.27,-0.85], p<.001)$ and $4+(B=-1.93,95 \% C I=[-2.19,-1.67])$. Moreover, when comparing the slopes in all stages and amyloidnegative controls with each other, there was a significant time $\times$ stage interaction for all stages, except the first stage (Table 3). The rate of decline accelerated with each successive stage (stage $1,-0.12$; stage $2,-0.32$; stage 3 , 1.06; stage 4, - 1.93; Table 3), compared to amyloidnegative individuals. Figure 1 displays the individual trajectories and group slopes of IADL decline for each stage. As can be seen in Fig. 1, there was a large variability in slopes between individuals in the AD continuum.

We additionally investigated the trajectories for community-based and memory clinic study cohorts and found that the results were largely similar, except that in community-based studies, the decline observed in stage 2 was not significantly different from the change in amyloid negatives. The results from these analyses can be found in the Supplementary Material.

\section{Activity-specific trajectories}

Both the relatively easy "preparing hot beverages" (estimate $-0.68,95 \% \mathrm{CI}=[-0.80,-0.57])$ and the more 


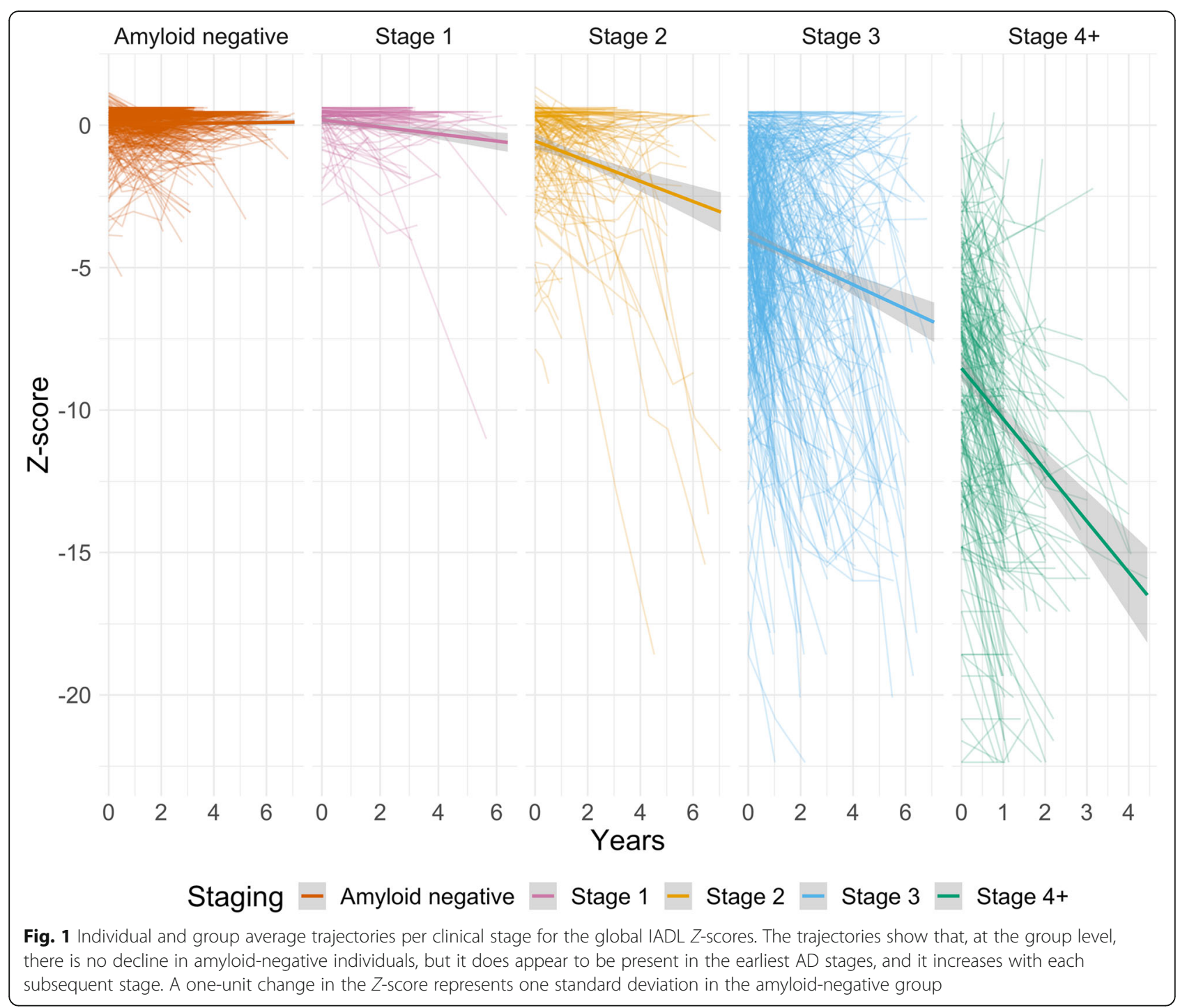

complex "managing paperwork" (estimate - 0.66, $95 \% \mathrm{CI}=[-0.75,-0.57])$ showed a similar, significant decline in the amyloid-positive group as a whole. Compared to the amyloid-negative group, individuals in stage 2 declined significantly faster on preparing hot beverages $(p<.001)$, whereas on managing paperwork, even individuals in stage 1 declined significantly faster $(p=.007)$. For both activities, there were no significant differences in rate of decline between stages 2 and 3. Those in stage $4+$ declined the fastest on both activities. Individual item responses are shown in Fig. 2.

\section{Discussion}

We demonstrated that the decline in daily functioning accelerates as $\mathrm{AD}$ progresses along the continuum from preclinical to symptomatic. This decline was distinct from the functional change observed in amyloidnegative, cognitively normal individuals. Furthermore, our data suggest that more complex activities, such as managing the paperwork, are especially sensitive to the earliest cognitive changes, showing a decline in the early prodromal stage.

Functional impairment has long been considered a defining feature of the transition from mild cognitive impairment to the dementia stage of $\mathrm{AD}[44,45]$. Accumulating evidence over the past decade shows that difficulties in cognitively complex activities may be seen in cognitively normal individuals who later progress to dementia [46-48]. This might indicate that these individuals have a lower level of functioning to start with, or it might suggest a decline in the pre-dementia stages. These findings have not previously been investigated in the context of the newly proposed NIA-AA stages. The staging criteria propose that detectible but mild functional impairment may be found in stage 3 and beyond, when performance on objective cognitive tests becomes 


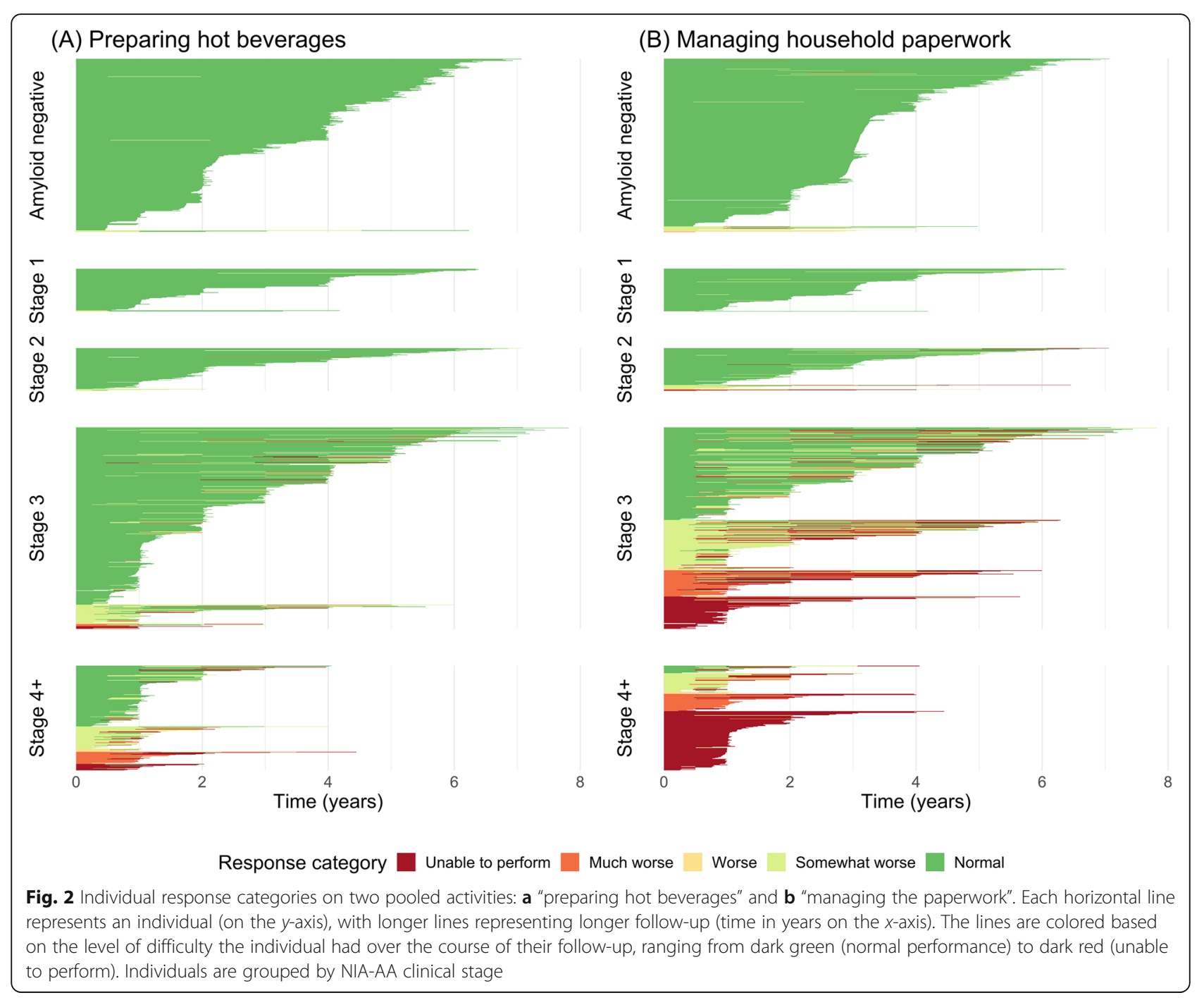

impaired [1]. We present evidence that decline in functional impairment may already be present in earlier stages. The decline we observed in stage 1 did not differ from the change in amyloid-negative individuals and may have been too subtle to be distinguished from normal aging-related decline in everyday functioning. Others have previously stated that sensitive measures of cognitive and functional impairment are needed to monitor disease progression in early stages, or to evaluate drug effectiveness in the context of AD clinical trials $[49,50]$. More convincingly, we observed a decline in stage 2 , before cognitive decline can be objectively measured using traditional cognitive tests. When compared to cognitively normal amyloid-negative individuals, there was a faster decline in all subsequent stages from stage 2 onward. In community-based studies, individuals in stage 2, which corresponds approximately to the concept of subjective cognitive decline (SCD), did not decline at a significantly different rate than amyloid-negative, cognitively normal individuals. It is possible that stage 2 individuals who have not visited a memory-clinic may be in some way different from those who have. Slot and colleagues [3] have previously shown that people with SCD who visited a memory clinic had an increased risk of progressing to dementia, compared to those who were included in community-based studies.

Our findings demonstrate that functional decline cooccurs with the earliest changes in cognition in the context of $\mathrm{AD}$, revealing the importance of assessing daily functioning in addition to cognitive functioning, particularly in early stages. Decline in cognition is assumed to cause functional impairment, not vice versa. However, many frequently used cognitive measures might not be sensitive enough to detect subtle cognitive changes [5153]. Our results justify combining sensitive IADL measures with sensitive cognitive tests for detecting such changes. Study partner-reported functional questionnaires have additional advantages in that they are easy to 
administer, have good ecological validity, and are strongly related to quality of life $[18,54]$. As such, our findings implicate an important benefit of including the measurement of everyday functioning in early AD stages for the evaluation of disease progression and potential intervention effectiveness, in addition to providing potential starting points for early non-pharmacological interventions targeting cognitive functioning.

\section{Limitations}

This study had a few limitations. Three questionnaires assessing slightly different aspects of cognitively complex everyday functioning and in reference to differing time frames were combined, and total scores were placed on a single scale by computing $Z$-scores for each instrument and merging them into a single score. Of all included activities, only a handful overlapped between all three questionnaires. Overall, however, they provide information about the same construct: higher-order cognitive functioning in everyday life, which was partly evidenced by the high correlation between two of the three measures. This justifies the combination of total scores into a single functional measure. Future undertakings could adapt a more sophisticated linking method, e.g., by using item response theory, giving more weight to questionnaires with favorable psychometric properties. A second limitation was that amyloid positivity was assessed using different techniques (i.e., PET and CSF) and using local cut-offs, so that an individual found positive in one cohort might not have been found positive in another. The average follow-up time was approximately 3 years. For the early stages ( 1 and 2), 3 years is a relatively short period of time, as preclinical AD duration is estimated to be about 10 years [55]. Further, we did not include longitudinal assessment of cognition and can therefore not be sure whether participants progressed from one clinical stage to the next. In consequence, it should be taken into account that our trajectories of change might not reflect each stage's entire duration. Finally, our study sample was comprised of convenience samples with relatively highly educated and mostly Caucasian participants. This has potentially caused a sample bias, and our findings may therefore not be directly applied to the global population.

\section{Strengths}

An important strength of this study was the large number of amyloid-positive individuals with a large age range and representing the entire AD continuum, who were followed over time and recruited in different study settings from both the USA and the Netherlands. By combining data from different cohorts, we aimed to overcome at least in part the sample bias. We ran sensitivity analyses (in Supplementary Material) and found that results were robust when removing either one of the cohorts, suggesting that the results are not driven by a single measure or cohort, supporting the robustness of our findings. Another strength was our approach to define clinical stages of severity, by using a careful operationalization of the NIA-AA clinical staging scheme and grouping individuals into four different clinical stages, which is a more refined method than relying solely on diagnostic status [56]. Additionally, IADL functioning as determined by the three questionnaires was not part of the staging criteria used in the current study, which has been a confound in many previous studies which divided groups into $\mathrm{MCI}$ and dementia. However, it must be noted that the staging was not completely independent of IADL as a construct, and that clinicians who determined disease symptom severity may not always have been blinded to the IADL scores, which may have influenced their classification. Our inclusion of an amyloidnegative comparison group indicates that the decline in IADL is disease specific and not a general aging effect.

Future research should include the other two major components of the NIA-AA model of AD, tau and neurodegeneration, to further investigate the relationship between function and AD pathology. Future studies should also incorporate and combine longitudinal clinical staging, so the continuous progression of cognitive and functional performance along the $\mathrm{AD}$ clinical spectrum can be investigated. Because functional impairment is not unique to $\mathrm{AD}$, future research should replicate our study in other neurodegenerative diseases, to investigate the relationship between other types of neurodegeneration and IADL functioning. Furthermore, as we noticed a lot of intra- and inter-individual variability in the change over time, it would be interesting to delve into these individual differences in future studies. Finally, we currently do not know when changes in functioning actually affect a person's ability to function independently. As such, investigating the clinical meaningfulness of these changes would be an important future endeavor.

\section{Conclusion}

To conclude, our findings suggest that increased difficulties with cognitively complex everyday activities may constitute a useful marker of early cognitive decline, in the pre-dementia stage of AD. Thus, the assessment of these complex activities may provide valuable information about the severity of cognitive symptoms, especially when measured longitudinally. Incorporating IADL measures alongside cognitive tests would allow for withinindividual everyday decline to be gauged in a cost- and time-effective way. We therefore recommend including a measure of functional difficulties in clinical trials at the stage of preclinical $\mathrm{AD}$, as well as in clinical practice. 


\section{Supplementary information}

Supplementary information accompanies this paper at https://doi.org/10. 1186/s13195-020-00706-2.

\section{Additional file 1.}

\section{Acknowledgements}

The authors thank all patients and participants in the studies, as well as everyone involved in data collection and data sharing.

Part of the data used in preparation of this article were obtained from the Alzheimer Disease Neuroimaging Initiative (ADNI) database (adni.loni.usc. edu). As such, the investigators within the ADNI contributed to the design and implementation of ADNI and/or provided data but did not participate in analysis or writing of this report. A complete listing of ADNI investigators can be found at: http://adni.loni.usc.edu/wp,content/uploads/how_to_apply/ ADNI_Acknowledgement_List.pdf.

\section{Authors' contributions}

M. A. Dubbelman, MSc: Author: Designed and conceptualized study; data analysis and interpretation; wrote the manuscript. He had full access to all the data in the study and takes responsibility for the integrity of the data and the accuracy of the data analysis. R. J. Jutten, PhD: Co-author: Designed and conceptualized study; supervision of project; Multiple revisions and integration of comments for the manuscript. S. E. Tomaszewski Farias, PhD: Coauthor: Collected and provided data; revised the manuscript. R. E. Amariglio, PhD: Co-author: Collected and provided data; methodological advise; revised the manuscript. R.F. Buckley, PhD: Co-author: Methodological advise; revised the manuscript. P. J. Visser, MD, PhD: Co-author: Collected and provided data; revised the manuscript. D. M. Rentz, PsyD: Co-author: Collected and provided data; revised the manuscript. K. A. Johnson, MD: Co-author: Collected and provided data; revised the manuscript. M. J. Properzi, PhD: Co-author: Assisted with data-management; revised the manuscript. A. Schultz: Coauthor: Assisted with data-management; revised the manuscript. N. Donovan: Co-author: Assisted with data-management; revised the manuscript. J. R. Gatchell: Co-author: Assisted with data-management; revised the manuscript. C. E. Teunissen, PhD: Co-author: Collected and provided data; revised the manuscript. B.N.M. van Berckel, MD, PhD: Co-author: Collected and provided data; revised the manuscript. W.M. van der Flier, PhD: Co-author: Collected and provided data; revised the manuscript. R.A. Sperling, MD: Co-author: Collected and provided data; revised the manuscript. K. V. Pap, PhD Co-author: Collected and provided data; revised the manuscript. P. Scheltens, MD, PhD: Co-author: Collected and provided data; revised the manuscript. G. A. Marshall, MD: Senior author: Designed and conceptualized study; supervision of project; multiple revisions and integration of comments for the manuscript. S. A. M. Sikkes, PhD: Senior author: Designed and conceptualized study; supervision of project; multiple revisions and integration of comments for the manuscript. The authors read and approved the final manuscript.

\section{Funding}

The funding sources had no role in the design and conduct of the study; collection, management, analysis, and interpretation of the data; preparation, review, or approval of the manuscript; and decision to submit the manuscript for publication.

The Harvard Aging Brain Study is funded by the National Institute on Aging (P01AG036694; Principal Investigators Reisa Sperling, Keith Johnson) with additional support from several philanthropic organizations. KVP (1K23AG053422-01) is supported by a K23 award from NIA and an award from the Alzheimer's Association.

Data collection and sharing for this project was funded by the Alzheimer's Disease Neuroimaging Initiative (ADNI) (National Institutes of Health, Grant U01 AG024904) and DOD ADNI (Department of Defense award number W81XWH-12-2-0012). ADNI is funded by the National Institute on Aging, the National Institute of Biomedical Imaging and Bioengineering, and through generous contributions from the following: AbbVie, Alzheimer's Association; Alzheimer's Drug Discovery Foundation; Araclon Biotech; BioClinica, Inc.; Biogen; Bristol-Myers Squibb Company; CereSpir, Inc.; Cogstate; Eisai Inc.; Elan Pharmaceuticals, Inc.; Eli Lilly and Company; Eurolmmun; F. Hoffmann-La Roche Ltd. and its affiliated company Genentech, Inc.; Fujirebio; GE Healthcare; IXICO Ltd.; Janssen Alzheimer Immunotherapy Research \& Development, LLC; Johnson \& Johnson Pharmaceutical Research \& Development LLC;
Lumosity; Lundbeck; Merck\&Co, Inc;; Meso ScaleDiagnostics, LLC; NeuroRx Research; Neurotrack Technologies; Novartis Pharmaceuticals Corporation; Pfizer Inc.; Piramal Imaging;Servier;Takeda Pharmaceutical Company; and Transition Therapeutics. The Canadian Institutes of Health Research is providing funds to support ADNI clinical sites in Canada. Private sector contributions are facilitated by the Foundation for the National Institutes of Health (http://www. fnih.org/). The grantee organization is the Northern California Institute for Research and Education, and the study is coordinated by the Alzheimer's Therapeutic Research Institute at the University of Southern California. ADNI data are disseminated by the Laboratory for Neuroimaging at the University of Southern California.

The NACC database is funded by NIA/NIH Grant U01 AG016976. NACC data are contributed by the NIA-funded ADCs: P30 AG019610 (PI Eric Reiman, MD), P30 AG013846 (PI Neil Kowall, MD), P30 AG062428-01 (PI James Leverenz, MD), P50 AG008702 (PI Scott Small, MD), P50 AG025688 (PI Allan Levey, MD, PhD), P50 AG047266 (PI Todd Golde, MD, PhD), P30 AG010133 (PI Andrew Saykin, PsyD), P50 AG005146 (PI Marilyn Albert, PhD), P30 AG062421-01 (PI Bradley Hyman, MD, PhD), P30 AG062422-01 (PI Ronald Petersen, MD, PhD), P50 AG005138 (PI Mary Sano, PhD), P30 AG008051 (PI Thomas Wisniewski, MD), P30 AG013854 (PI Robert Vassar, PhD), P30 AG008017 (PI Jeffrey Kaye, MD), P30 AG010161 (PI David Bennett, MD), P50 AG047366 (PI Victor Henderson, MD, MS), P30 AG010129 (PI Charles DeCarli, MD), P50 AG016573 (PI Frank LaFerla, PhD), P30 AG062429-01(PI James Brewer, MD, PhD), P50 AG023501 (PI Bruce Miller, MD), P30 AG035982 (PI Russell Swerdlow, MD), P30 AG028383 (PI Linda Van Eldik, PhD), P30 AG053760 (PI Henry Paulson, MD, PhD), P30 AG010124 (PI John Trojanowski, MD, PhD), P50 AG005133 (PI Oscar Lopez, MD), P50 AG005142 (PI Helena Chui, MD), P30 AG012300 (PI Roger Rosenberg, MD), P30 AG049638 (PI Suzanne Craft, PhD), P50 AG005136 (PI Thomas Grabowski, MD), P30 AG062715-01 (PI Sanjay Asthana, MD, FRCP), P50 AG005681 (PI John Morris, MD), and P50 AG047270 (PI Stephen Strittmatter, MD, PhD).

The Alzheimer Center Amsterdam is supported by Alzheimer Nederland and Stichting VUmc Fonds. The clinical database structure of the Amsterdam Dementia Cohort (ADC) was developed with funding from Stichting Dioraphte.

The work for the EMIF cohorts has received support from the EU/EFPIA Innovative Medicines Initiative Joint Undertaking (EMIF grant no. 115372). It also received in kind sponsoring of the CSF assay from ADx NeuroSciences and Euroimmun, and the PET-tracer 18F-flutemetamol from GE Healthcare.

\section{Availability of data and materials}

The data and materials used in this study can be made available by the corresponding author upon request.

\section{Ethics approval and consent to participate}

The studies of which we used data in this study have been approved by their institutions' respective ethical review boards. All subjects provided written informed consent for the use of their data for research purposes, in accordance with the Declaration of Helsinki.

\section{Consent for publication}

Not applicable.

\section{Competing interests}

MAD, RJJ, SETF, REA, RFB, PJV, DMR, KAJ, MJP, AS, ND, JRG, BNMB, and RAS report no disclosures relevant to this manuscript. SAMS is supported by grants from JPND and Zon-MW and has provided consultancy services in the past 2 years for Nutricia and Takeda. All funds were paid to her institution. GAM has received research salary support from Eisai Inc., Eli Lilly and Company, Janssen Alzheimer Immunotherapy, Novartis, and Genentech. Additionally, GAM has served as a consultant for Grifols Shared Services North America, Inc., Eisai Inc., and Pfizer. WMF holds the Pasman chair. CET received grants from the European Commission, the Dutch Research Council (ZonMW), Association of Frontotemporal Dementia/Alzheimer's Drug Discovery Foundation, The Weston Brain Institute, Alzheimer Nederland. CET has functioned in advisory boards of Roche, received non-financial support in the form of research consumables from ADxNeurosciences and Euroimmun, performed contract research, or received grants from Probiodrug, Biogen, Esai, Toyama, Janssen prevention center, Boehringer, AxonNeurosciences, EIP farma, PeopleBio, and Roche. KVP has served as a paid consultant for Biogen. 


\section{Author details}

'Department of Neurology, Amsterdam Neuroscience, Alzheimer Center Amsterdam, Vrije Universiteit Amsterdam, Amsterdam UMC, location VUmc, P.O. Box 7057, 1007 MB Amsterdam, The Netherlands. ${ }^{2}$ Department of Neurology, University of California, Davis, Davis, CA, USA. ${ }^{3}$ Department of Neurology, Massachusetts General Hospital, Harvard Medical School, Boston, MA, USA. " Department of Neurology, Brigham and Women's Hospital, Harvard Medical School, Boston, MA, USA. ${ }^{5}$ Melbourne School of Psychological Sciences, University of Melbourne, Melbourne, Victoria, Australia. ${ }^{6}$ Department of Psychiatry and Neuropsychology, School for Mental Health and Neuroscience, Maastricht University, Maastricht, The Netherlands. ${ }^{7}$ Department of Radiology, Massachusetts General Hospital, Harvard Medical School, Boston, MA, USA. 'Department of Psychiatry, Brigham and Women's Hospital, Harvard Medical School, Boston, MA, USA. ${ }^{9}$ Department of Psychiatry, Massachusetts General Hospital, Harvard Medical School, Boston, MA, USA. ${ }^{10}$ Neurochemistry Laboratory, Department of Clinical Chemistry, Amsterdam UMC, Vrije Universiteit Amsterdam, Amsterdam, The Netherlands. ${ }^{11}$ Department of Radiology and Nuclear Medicine, Amsterdam UMC, Vrije Universiteit Amsterdam, Amsterdam, The Netherlands. ${ }^{12}$ Department of Clinical, Neuro- \& Developmental Psychology, Vrije Universiteit Amsterdam, Amsterdam, The Netherlands.

Received: 23 July 2020 Accepted: 12 October 2020

Published online: 29 October 2020

\section{References}

1. Jack CR Jr, Bennett DA, Blennow K, Carrillo MC, Dunn B, Haeberlein SB, et al. NIA-AA research framework: toward a biological definition of Alzheimer's disease. Alzheimers Dement. 2018;14(4):535-62.

2. Jessen $F$, Amariglio RE, Van Boxtel M, Breteler MMB, Ceccaldi M, Chételat G, et al. A conceptual framework for research on subjective cognitive decline in preclinical Alzheimer's disease. Alzheimers Dement. 2014;10(6):844-52.

3. Slot RER, Sikkes SAM, Berkhof J, Brodaty H, Buckley R, Cavedo E, et al. Subjective cognitive decline and rates of incident Alzheimer's disease and non-Alzheimer's disease dementia. Alzheimers Dement. 2019;15(3):465-76.

4. Amieva H, Le Goff M, Millet X, Orgogozo JM, Peres K, Barberger-Gateau P, et al. Prodromal Alzheimer's disease: successive emergence of the clinical symptoms. Ann Neurol. 2008;64(5):492-8.

5. Peres K, Helmer C, Amieva H, Orgogozo JM, Rouch I, Dartigues JF, et al. Natural history of decline in instrumental activities of daily living performance over the 10 years preceding the clinical diagnosis of dementia: a prospective population-based study. J Am Geriatr Soc. 2008;56(1):37-44.

6. Albert MS, DeKosky ST, Dickson D, Dubois B, Feldman HH, Fox NC, et al. The diagnosis of mild cognitive impairment due to Alzheimer's disease: recommendations from the National Institute on Aging-Alzheimer's Association workgroups on diagnostic guidelines for Alzheimer's disease. Alzheimers Dement. 2011;7(3):270-9.

7. Marshall GA, Rentz DM, Frey MT, Locascio JJ, Johnson KA, Sperling RA, et al, Executive function and instrumental activities of daily living in mild cognitive impairment and Alzheimer's disease. Alzheimers Dement. 2011; 7(3):300-8.

8. Morris JC. Revised criteria for mild cognitive impairment may compromise the diagnosis of Alzheimer disease dementia. Arch Neurol. 2012;69(6):700-8.

9. Triebel KL, Martin R, Griffith HR, Marceaux J, Okonkwo OC, Harrell L, et al. Declining financial capacity in mild cognitive impairment: a 1-year longitudinal study. Neurology. 2009;73(12):928-34.

10. Goldberg TE, Koppel J, Keehlisen L, Christen E, Dreses-Werringloer U, Conejero-Goldberg C, et al. Performance-based measures of everyday function in mild cognitive impairment. Am J Psychiatry. 2010;167(7):845-53.

11. Marshall GA, Dekhtyar M, Bruno JM, Jethwani K, Amariglio RE, Johnson KA, et al. The Harvard Automated Phone Task: new performance-based activities of daily living tests for early Alzheimer's disease. J Prev Alzheimers Dis. 2015; 2(4):242-53.

12. Czaja SJ, Loewenstein DA, Sabbag SA, Curiel RE, Crocco E, Harvey PD. A novel method for direct assessment of everyday competence among older adults. J Alzheimers Dis. 2017;57(4):1229-38.

13. Verlinden VJA, Van der Geest JN, De Bruijn RFAG, Hofman A, Koudstaal PJ, Arfan IM. Trajectories of decline in cognition and daily functioning in preclinical dementia. Alzheimers Dement. 2016;12(2):144-53.

14. Marshall GA, Aghjayan SL, Dekhtyar M, Locascio JJ, Jethwani K, Amariglio RE, et al. Activities of daily living measured by the Harvard Automated Phone
Task track with cognitive decline over time in non-demented elderly. J Prev Alzheimers Dis. 2017;4(2):81-6.

15. Marshall GA, Zoller AS, Kelly KE, Amariglio RE, Locascio JJ, Johnson KA, et al. Everyday cognition scale items that best discriminate between and predict progression from clinically normal to mild cognitive impairment. Curr Alzheimer Res. 2014;11(9):853-61.

16. Marshall GA, Zoller AS, Lorius N, Amariglio RE, Locascio JJ, Johnson KA, et al. Functional activities questionnaire items that best discriminate and predict progression from clinically normal to mild cognitive impairment. Curr Alzheimer Res. 2015;12(5):493-502.

17. Zoller AS, Gaal IM, Royer CA, Locascio JJ, Amariglio RE, Blacker D, et al. SISTM-IR activities of daily living items that best discriminate clinically normal elderly from those with mild cognitive impairment. Curr Alzheimer Res. 2014;11(8):785-91.

18. Edgar CJ, Vradenburg G, Hassenstab J. The 2018 Revised FDA guidance for early Alzheimer's disease: establishing the meaningfulness of treatment effects. J Prev Alz Dis 2019;6:223-7.

19. Springate BA, Tremont G. Dimensions of caregiver burden in dementia: impact of demographic, mood, and care recipient variables. Am J Geriatr Psychiatry. 2014;22(3):294-300.

20. Jutten RJ, Harrison J, de Jong FJ, Aleman A, Ritchie CW, Scheltens P, et al. A composite measure of cognitive and functional progression in Alzheimer's disease: Design of the Capturing Changes in Cognition study. Alzheimers Dement (N Y). 2017;3(1):130-8.

21. Dagley A, LaPoint M, Huijbers W, Hedden T, McLaren DG, Chatwal JP, et al. Harvard Aging Brain Study: dataset and accessibility. Neuroimage. 2017; 144(Pt B):255-8.

22. Aisen PS, Petersen RC, Donohue MC, Gamst A, Raman R, Thomas RG, et al Clinical Core of the Alzheimer's Disease Neuroimaging Initiative: progress and plans. Alzheimers Dement. 2010;6(3):239-46.

23. Beekly DL, Ramos EM, Lee WW, Deitrich WD, Jacka ME, Wu J, et al. The National Alzheimer's Coordinating Center (NACC) database: the uniform data set. Alzheimer Dis Assoc Disord. 2007;21(3):249-58.

24. van der Flier WM, Scheltens P. Amsterdam dementia cohort: performing research to optimize care. J Alzheimers Dis. 2018;62(3):1091-111.

25. Konijnenberg E, Carter SF, Ten Kate M, den Braber A, Tomassen J, Amadi C, et al. The EMIF-AD PreclinAD study: study design and baseline cohort overview. Alzheimers Res Ther. 2018;10(1):75.

26. Legdeur N, Badissi M, Carter SF, de Crom S, van de Kreeke A, Vreeswijk R, et al. Resilience to cognitive impairment in the oldest-old: design of the EMIF-AD 90+ study. BMC Geriatr. 2018;18(1):289.

27. Mormino EC, Betensky RA, Hedden T, Schultz AP, Ward A, Huijbers W, et al. Amyloid and APOE epsilon4 interact to influence short-term decline in preclinical Alzheimer disease. Neurology. 2014;82(20):1760-7.

28. Clark CM, Schneider JA, Bedell BJ, Beach TG, Bilker WB, Mintun MA, et al. Use of florbetapir-PET for imaging beta-amyloid pathology. JAMA. 2011; 305(3):275-83.

29. Besser L, Kukull W, Knopman DS, Chui H, Galasko D, Weintraub S, et al. Version 3 of the National Alzheimer's Coordinating Center's Uniform Data Set. Alzheimer Dis Assoc Disord. 2018;32(4):351-8.

30. Tijms BM, Willemse EAJ, Zwan MD, Mulder SD, Visser PJ, Van Berckel BNM, et al. Unbiased approach to counteract upward drift in cerebrospinal fluid amyloid- $\beta$ 1-42 analysis results. Clin Chem. 2018;64(3):576-85.

31. Jutten RJ, Sikkes SAM, Amariglio RE, Buckley RF, Properzi MJ, Marshall GA, Rentz DM, Johnson KA, Teunissen CE, Van Berckel BNM, Van der Flier WM, Scheltens P, Sperling RA, Papp KV. For the Alzheimer Disease Neuroimaging Initiative and National Alzheimer's Coordinating Center, the Harvard Aging Brain Study, and the Alzheimer Dementia Cohort. Identifying Sensitive Measures of Cognitive Decline at Different Clinical Stages of Alzheimer's Disease. 2020. https://doi.org/10.1017/S1355617720000934.

32. Pfeffer RI, Kurosaki TT, Harrah CH Jr, Chance JM, Filos S. Measurement of functional activities in older adults in the community. J Gerontol. 1982;37(3): 323-9.

33. Farias ST, Mungas D, Reed BR, Cahn-Weiner D, Jagust W, Baynes K, et al. The measurement of everyday cognition (ECog): scale development and psychometric properties. Neuropsychology. 2008;22(4):531-44.

34. Farias ST, Park LQ, Harvey DJ, Simon C, Reed BR, Carmichael O, et al. Everyday cognition in older adults: associations with neuropsychological performance and structural brain imaging. J Int Neuropsychol Soc. 2013; 19(4):430-41. 
35. Sikkes SAM, de Lange-de Klerk ES, Pijnenburg YAL, Gillissen F, Romkes R, $\mathrm{Knol} \mathrm{DL}$, et al. A new informant-based questionnaire for instrumental activities of daily living in dementia. Alzheimers Dement. 2012;8(6):536-43.

36. Dubbelman MA, Verrijp M, Facal D, Sanchez-Benavides G, Brown LJE, van der Flier WM, et al. The influence of diversity on the measurement of functional impairment: an international validation of the Amsterdam IADL Questionnaire in eight countries. Alzheimers Dement (Amst). 2020;12(1):e12021.

37. Jutten RJ, Peeters CFW, Leijdesdorff SMJ, Visser PJ, Maier AB, Terwee CB, et al. Detecting functional decline from normal aging to dementia: development and validation of a short version of the Amsterdam IADL Questionnaire. Alzheimers Dement (Amst). 2017;8:26-35.

38. Koster N, Knol DL, Uitdehaag BM, Scheltens P, Sikkes SAM. The sensitivity to change over time of the Amsterdam IADL Questionnaire((c)). Alzheimers Dement. 2015;11(10):1231-40.

39. Sikkes SAM, Knol DL, Pijnenburg YAL, de Lange-de Klerk ES, Uitdehaag BM, Scheltens P. Validation of the Amsterdam IADL Questionnaire(c), a new tool to measure instrumental activities of daily living in dementia. Neuroepidemiology. 2013;41(1):35-41.

40. Sikkes SAM, Pijnenburg YAL, Knol DL, de Lange-de Klerk ES, Scheltens $P$, Uitdehaag BM. Assessment of instrumental activities of daily living in dementia: diagnostic value of the Amsterdam Instrumental Activities of Daily Living Questionnaire. J Geriatr Psychiatry Neurol. 2013;26(4):244-50.

41. Bates D, Machler M, Bolker BM, Walker SC. Fitting linear mixed-effects models using Ime4. J Stat Softw. 2015;67(1):1-48.

42. R Core Team. R: A language and environment for statistical computing. 4.0.2 ed 2020.

43. StataCorp. Stata Statistical Software: Release 14. 14th ed. College Station: StataCorp LP; 2015.

44. Scheltens P, Blennow K, Breteler MMB, De Strooper B, Frisoni GB, Salloway S, et al. Alzheimer's disease. Lancet. 2016;388(10043):505-17.

45. American Psychiatric Association. Diagnostic and statistical manual of mental disorders. 4th ed., text rev. ed. Washington, DC: American Psychiatric Association; 2000.

46. Marshall GA, Amariglio RE, Sperling RA, Rentz DM. Activities of daily living: where do they fit in the diagnosis of Alzheimer's disease? Neurodegener Dis Manag. 2012;2(5):483-91.

47. Farias ST, Chou E, Harvey DJ, Mungas D, Reed B, DeCarli C, et al. Longitudinal trajectories of everyday function by diagnostic status. Psychol Aging. 2013;28(4):1070-5.

48. Sikkes SAM, Visser PJ, Knol DL, de Lange-de Klerk ES, Tsolaki M, Frisoni GB, et al. Do instrumental activities of daily living predict dementia at 1- and 2year follow-up? Findings from the Development of Screening guidelines and diagnostic Criteria for Predementia Alzheimer's disease study. J Am Geriatr Soc. 2011;59(12):2273-81.

49. Weintraub S, Carrillo MC, Farias ST, Goldberg TE, Hendrix JA, Jaeger J, et al. Measuring cognition and function in the preclinical stage of Alzheimer's disease. Alzheimers Dement (N Y). 2018;4:64-75.

50. Snyder PJ, Kahle-Wrobleski K, Brannan S, Miller DS, Schindler RJ, DeSanti S, et al. Assessing cognition and function in Alzheimer's disease clinical trials: do we have the right tools? Alzheimers Dement. 2014;10(6):853-60.

51. Rentz DM, Parra Rodriguez MA, Amariglio R, Stern Y, Sperling R, Ferris S. Promising developments in neuropsychological approaches for the detection of preclinical Alzheimer's disease: a selective review. Alzheimers Res Ther. 2013;5(6):58.

52. Mortamais M, Ash JA, Harrison J, Kaye J, Kramer J, Randolph C, et al. Detecting cognitive changes in preclinical Alzheimer's disease: a review of its feasibility. Alzheimers Dement. 2017;13(4):468-92.

53. Mura T, Proust-Lima C, Jacamin-Gadda H, Akbaraly TN, Touchon J, Dubois B, et al. Measuring cognitive change in subjects with prodromal Alzheimer's disease. J Neurol Neurosurg Psychiatry. 2014;85(4):363-70.

54. Sikkes SAM, De Rotrou J. A qualitative review of instrumental activities of daily living in dementia: what's cooking? Neurodegener Dis Manag. 2014; 4(5):393-400.

55. Vermunt L, Sikkes SAM, van den Hout A, Handels R, Bos I, van der Flier WM, et al. Duration of preclinical, prodromal, and dementia stages of Alzheimer's disease in relation to age, sex, and APOE genotype. Alzheimers Dement. 2019;15(7):888-98.

56. Jack CR Jr, Therneau TM, Weigand SD, Wiste HJ, Knopman DS, Vemuri P, et al. Prevalence of biologically vs clinically defined Alzheimer spectrum entities using the National Institute on Aging-Alzheimer's Association research framework. JAMA Neurol. 2019;76(10):1174-83.

\section{Publisher's Note}

Springer Nature remains neutral with regard to jurisdictional claims in published maps and institutional affiliations.
Ready to submit your research? Choose BMC and benefit from:

- fast, convenient online submission

- thorough peer review by experienced researchers in your field

- rapid publication on acceptance

- support for research data, including large and complex data types

- gold Open Access which fosters wider collaboration and increased citations

- maximum visibility for your research: over $100 \mathrm{M}$ website views per year

At BMC, research is always in progress.

Learn more biomedcentral.com/submissions 